\title{
Economic diagnostics of the quality of higher education and the basics of its modeling
}

\author{
Sotvoldiev Nodirbek Jurabaevich ${ }^{1}$, Sirojiddinov Ikromiddin Kutbiddinovich ${ }^{2}$ \\ ${ }^{1,2}$ Associate Professor of Economics, Namangan State University \\ PZ-20170929727 Applied Research Project Manager, Republic of Uzbekistan
}

Email: nodirbek.s@mail.ru

\begin{abstract}
The article analyzes the quality of higher education and its economic diagnosis. Defined methods for modeling economic diagnostics. There are scientific conclusions and practical recommendations on the economic assessment of the quality of higher education.
\end{abstract}

Keywords: quality of higher education, economic diagnostics, higher education institution, model, professor-teacher, unit of measure, final indicators.

\section{INTRODUCTION}

Radical changes are taking place in the system of higher education in Uzbekistan. The measures taken in this system are aimed at dramatically improving the quality of education, substantially strengthening the material and technical and financial base, expanding economic resources, increasing the independence and initiative of higher education institutions (HEIs) as economic entities. Modern systems of higher education are based on the widespread use of market mechanisms. At the same time, the main goal is to achieve higher quality and higher quality of higher education through the effective use of economic resources.

In this regard, the President of the Republic of Uzbekistan Sh.Mirziyoyev noted: “... we need to logically complete our adopted national programs on education. To this end, the most important task of the Government, relevant ministries and agencies, and the entire education system, our respected teachers and professors is to educate the younger generation and educate them physically and spiritually. It is time to move our work to a new level, creating modern jobs for our children and ensuring their rightful place in life "[1].

To do this, it is necessary to develop management decisions based on what resources are required to achieve the results required for the activities of the HEIs and the causes of change. In this regard, the relevance of the chosen topic determines the quality of higher education outcomes and the development of scientific proposals and practical recommendations for improving the mechanism of economic diagnostics.

\section{LITERATURE REVIEW}

The economics of higher education has been studied by foreign and domestic scientists. Research areas can be divided into several groups: theoretical and methodological studies; issues of public administration; organizational and legal and institutional aspects; educational services market; marketing and quality management in higher education; social responsibility of higher education and so on. In these studies, the development of universal and economic relations, as well as the quality, regularities, theories, and concepts of education, were developed.

The notion of quality of higher education has been widely adopted by stakeholders and various competent organizations. Sources of international importance include information on its three components: education; normative documents of education; learning environment [3]. In the study of L. Wlaskin and L. Grinberg, the quality of higher education is multidimensional, multi-level and dynamic, depending on the contextual unity of the educational model, the mission and objectives of the institution, and the specific standards. V.Levshina's research presents many controversial points, namely two aspects of the quality of higher education: the quality of the educational process; Description of quality assurance systems. This 
requires a comprehensive analysis of the content of education, the process of preparing applicants, teaching staff, information and methodological support, educational technologies and research activities [5].

In Uzbekistan, there is a research on economic aspects of the quality of higher education. Financing and management of higher education are widely covered. In particular, N. Mirkurbanov believes that regardless of the type and stage of national economy and education, its existence and functioning in a market economy is based on the quality criteria. Quality assurance in higher education contributes to the training of qualified staff in the region. This is an axiom that does not require evidence, and has become a major issue for the Government of the Republic of Uzbekistan, the Ministry of Higher and Secondary Special Education, and higher education institutions. According to A. Karimov, L. Peregudov and M. Saidov, the quality of higher education is a multi-faceted concept. It should cover all activities and activities in the field of education - academic and academic programs, research and scholarships, full staffing, training of students, buildings, logistics and equipment, welfare of the community and academic environment. ].

These studies do not comprehensively investigate such issues as the optimal quality of higher education, social impact, and the use of resources to ensure the quality of higher education. From this point of view, economic diagnostics of the quality of higher education, development of methodological approaches and determination of strategic objectives are of great importance.

\section{RESEARCH METHODOLOGY}

This study used several economic, mathematical, and modeling methods that characterize the quality of higher education and its economic diagnosis. In particular, the economic analysis was performed using only statistical data without direct access to the system. It evaluates the extent to which resources are mobilized through the Black Box model of economic diagnostics. Such methods have revealed the peculiarities of economic diagnostics of higher education quality and its modeling processes.

\section{ANALYSIS AND RESULTS}

As the world experience shows, as a result of the liberalization of the economy, the positive role of market relations in the socio-economic life occurs. The market form of social relations promotes the efficient use of resources available to the public, saving and at the same time improving their quality.

Socio-economic development of the 20th century and the present is caused by the sharp increase of human factor in the structure of resources. On the one hand, this resource has been raised to a qualitatively new level, and, on the other hand, the public's investments in its creation are increasingly being channeled.

Higher education plays a special role in the formation of human capital. There is an increase in the share of highly educated specialists in total employment in the national economy. Such necessity is also characteristic for Uzbekistan. Therefore, the Strategy of Actions for the Further Development of the Republic of Uzbekistan in 2017-2021 sets out to significantly increase the admission quota for undergraduate and graduate programs in higher educational institutions of the country.

Currently, higher education institutions (HEIs) have to operate in a broad and deep market environment. That is why the importance of the financial sustainability of HEIs is growing. Rational arrangement of the economic processes will promote consistent and high-quality educational and research activities in HEIs, effective use of scientific and pedagogical potential and material and technical base. Clearly, the financial and economic potential and sustainability of the university is of particular importance, and it is becoming increasingly important to develop measures for assessing the quality of education through economic diagnostics.

In our view, the economic diagnosis of higher education and its elements can be explained as follows (Figure 1):

The content of the diagnostic process - to conduct research aimed at identifying the impact of costs on the quality of education and comparing it with the expected effect;

diagnostic object - the higher educational institution or its departments;

The purpose of diagnostics is to evaluate the position and changes in the institution of higher education in society or in the system of higher education;

diagnostic tasks - development of measures to ensure and improve the compatibility of elements in the system, control of deficiencies based on certain criteria.

The use of economic diagnostics for the quality of higher education requires the following methods of economic analysis: 
research using direct statistical data and sophisticated methods of economic analysis without directly entering the system;

examination of systematized data;

research using mathematical and statistical methods;

use of dynamic programming and mathematical models;

use linear programming that provides optimization to achieve quantitative expression goals.

As can be seen from the above, a comprehensive economic diagnosis of HEIs can be viewed as a five-step analytical process. These stages are interconnected and organized so that an optimal result can be achieved. Each step is based on the previous one.

The main purpose of the diagnostics is to assess the financial and economic condition of the university and to identify sustainability and to identify opportunities and resources for development. To achieve this goal, of course, the main directions of financial and economic policy will be used. Diagnostics is one of the important tools in pursuing this policy. Diagnostic results can be compared to the position of the HEI in society or to assess changes in its status at different intervals.

At present, we believe that diagnosis based on financial ratios analysis can be applied to HEIs as well. Of course, it should take into account the specifics of educational services. In many developed countries, the activities of universities are quite commercial. The commercialization of higher education institutions is measured by the potential that market mechanisms can provide, and can be seen as conditions for improving the quality and scope of education. It is also assumed that the quality of higher education is the first factor that determines the country's competitiveness. Therefore, the activities of HEIs in Uzbekistan should also be seen as a natural process of increasing commercialization.

Full regulation of the financial and economic activity of higher educational institutions by the higher state authorities or the low level of freedom as an economic subject limits its economic responsibility and initiative. Under these conditions, there is no need to diagnose the economic condition and quality of higher education.

The need for efficient use of economic resources in the context of the limited independence of higher education institutions cannot be ruled out. However, in this situation, the rule "we will work according to how many resources we have been provided" applies. Efficient use of resources is not a priority. Even resource savings can lead to less segregation. In this context, HEIs as economic entities do not need economic diagnostics. This task is passed to the higher governing body of higher education. However, the upper body also has a position similar to that of the HEI before the higher body. Generally, it is difficult to find a governing body that needs economic evaluation of higher education and needs it.

In the context of the liberalization of socio-economic life, the role of the university in the society will change dramatically. At the same time, it is necessary to provide the society with a highly skilled, creative and initiative person in line with the requirements of the knowledge economy, and on the other hand, to carry out the activities of HEIs using market mechanisms. Higher education will need to function as a component of the services sector, provide its services and receive a corresponding fee. This will increase the competitiveness of higher education services and result in pricing services based on market principles. In this context, it is crucial that HEIs use economic resources wisely and achieve high results.

In particular, in order to radically improve the quality of education in higher education institutions, to ensure their active participation in the wide-scale reforms implemented in the country, consistent implementation of the tasks set in the Strategy of Action on the five priority directions of development of the Republic of Uzbekistan in 2017-2021. improving the quality of education and their active participation in large-scale reforms in the country Decree of the President of the Republic of Uzbekistan "On additional measures to ensure the safety". As part of this Decree, a Roadmap was developed to improve the quality of education in higher education institutions and to ensure their active participation in large-scale reforms in the country. [2]

1. Improving the legal framework for improving the quality of education in higher education institutions;

2. Organizational measures to improve the quality and effectiveness of education in higher education institutions;

3. Increasing the participation and initiative of higher education institutions in large-scale reforms in the country; 
4. To inform the general public on the content and essence of the ongoing reforms in the state and society, and on the fundamental reforms underway in the public domain, through television and other media;

5. Effective organization of the implementation of research results and innovative development of faculty, young scientists and students of higher educational institutions;

6. Increase the responsibility of higher education institutions for their active participation in the country's reform process.

These measures determine the economic approach to the quality of higher education, radically change its place in the society of higher education, and ensure the rational use of economic resources and achieving high results.

In this context, economic diagnostics of the quality of higher education is an important element of management in the field. In turn, economic diagnostics can successfully fulfill the set objectives if implemented consistently using the basic principles of systematic analysis.

It is well known that decisions that make up the core content of governance are made based on the problem. The problem is the imbalance between the situation and the result that needs to be achieved. A diagnosis should be made to determine this discrepancy. This requires quantitative assessment of various aspects of the situation. Quantitative recording of economic indicators will determine how well they meet certain criteria (goals, norms, forecasts, etc.). Hence, the diagnosis is based on a model that is expressed in quantities. At the same time, the quantitative data obtained should be explored in meaning. Therefore, the diagnostic model is of analytical nature. Generally, economic diagnostics is based on a model that is based on quantitative evaluation and content analysis.

Diagnostics is performed using direct statistical data and sophisticated methods of economic analysis without direct access to the system. One of the most common rules for economic diagnostics is the Black Box model [8]. This includes the inputs (outputs) and outputs or outputs into the black box. It is believed that there is no faith in the analysis of the processes occurring in the black box. Economic diagnostics assesses how much inflow flows into outputs or how efficiently the resources are involved. Number and quality of students (pre-higher education level) as inputs or resources in HEIs, number of faculty members, quality and teaching load, available material and technical resources (educational and support buildings, laboratories, technical equipment, materials) - communication, financial resources appear. The HEI prepares highly qualified personnel and conducts research activities using the attracted resources (Fig 1).

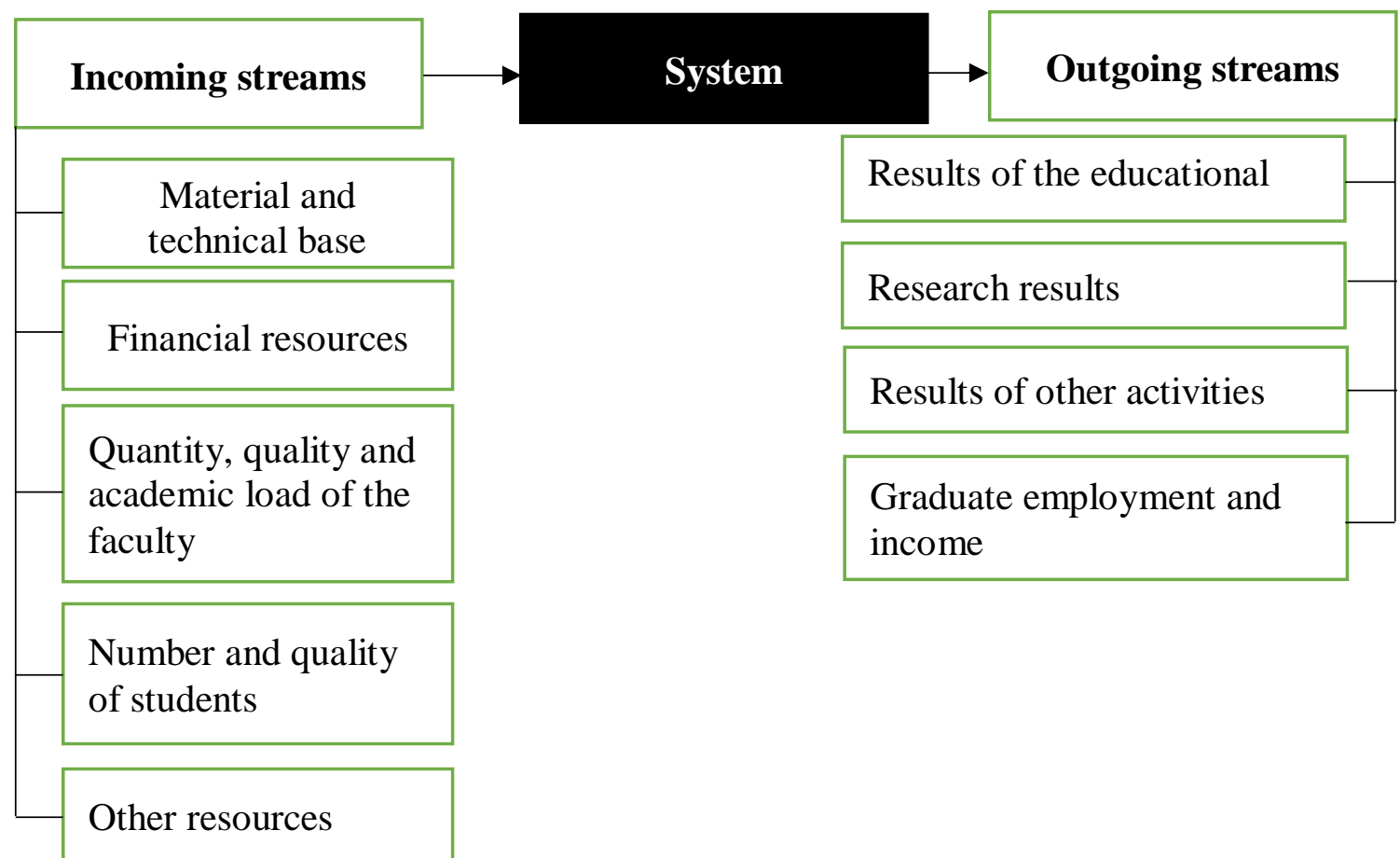

Fig 1. Economic Diagnosis of Higher Education Quality and its Black Box Model ${ }^{1}$

${ }^{1}$ Developed by the author. 
Although the "black box" model is quite simple from the outside, its application is complicated. This is because inputs must be expressed by any indicator. For example, one of the indicators that characterizes the material and technical base of the HEI is the size of the study areas measured in square meters. However, this indicator does not indicate that the learning areas are appropriate for the learning objectives. Many universities operate in customized buildings. Of course, those who work in specialized buildings have the advantage.

In a simple approach, the activities of the faculty at the HEI are seen as transparent and provide a two-hour academic course. Uses advanced pedagogical technology or "achieves high results with minimal effort". If we approach the teaching staff through the Black Box module, our conclusions will change slightly. The teaching load of an assistant or teacher is set at around 1000 hours. This means that the teacher has 1,000 hours of direct communication with students. In the academic year, classroom classes last for an average of 36 weeks, during which the instructor must conduct 1,000: $36=28$ hours of instruction per week. The higher education labor law provides for a six-day working week and six-hour working hours. This means that 36 hours a week ( 6 days $* 6$ hours), 36-28 $=8$ hours a week for teacher preparation work, which is not enough. Applying the "black box" model, the 1,000-hour load does not provide the required quality of education and the financial and other resources involved are not justified (Table 1).

Curriculum load and preparatory work of the faculty of the university ${ }^{2}$

Table 1

\begin{tabular}{|l|l|c|c|c|c|}
\hline \multirow{2}{*}{ № } & \multicolumn{1}{|c|}{ The teaching staff } & $\begin{array}{c}\text { Annual } \\
\text { academic } \\
\text { load, hours } \\
(\mathbf{3 6} \text { weeks) }\end{array}$ & $\begin{array}{c}\text { Study load } \\
\text { per week, } \\
\text { hours (1 } \\
\text { week (36 } \\
\text { weeks) }\end{array}$ & $\begin{array}{c}\text { Preparation } \\
\text { works for a } \\
\text { week, hours } \\
(\mathbf{( 3 6} \text { hours) } \mathbf{- 2})\end{array}$ & $\begin{array}{c}\text { Percentage of } \\
\text { preparatory } \\
\text { work per } \\
\text { week, \% (3: } \\
\mathbf{2 x 1 0 0 )}\end{array}$ \\
\cline { 3 - 6 } & $\mathbf{1}$ & $\mathbf{2}$ & $\mathbf{3}$ & $\mathbf{4}$ \\
\hline 1 & Head of the department & 770 & 21 & 15 & 68 \\
\hline 2 & Professor & 800 & 22 & 14 & 62 \\
\hline 3 & Associate Professor & 850 & 24 & 12 & 52 \\
\hline 4 & Senior teacher & 900 & 25 & 11 & 44 \\
\hline 5 & Teacher-assistant & 1000 & 28 & 8 & 30 \\
\hline
\end{tabular}

Through the Black Box model, the approach allows decision-making to prioritize the content of the result, ie the quality. At the same time, teaching faculty in academic groups is regarded as an educational process. One acupuncture group can accommodate up to 25 students. In some cases, depending on the complexity of the educational process, academic groups are divided into 2 subgroups. Thus, the average number of students per faculty of 10.5 is considered appropriate for higher education and the number of states is calculated. This approach does not take into account the quality of education, and is determined by how many students a faculty member is engaged in, or who may be involved in teaching. In addition, the key performance indicator of the faculty is how many hours they have completed the academic load. In fact, the quality of education is, on the one hand, measured by the way the faculty prepares for the course and organizes it. On the other hand, it is reflected in the combined scientific and pedagogical potential of the faculty. The high scientific and pedagogical potential is a reflection of the accumulation process in the university. Generally, it is possible to generate quantitative indicators of how many students the faculty can cover, how much the teaching load, and the scientific and pedagogical potential. These indicators do not represent the expected outcome of education - the quality of each academic hour.

In world practice, the number of students a faculty member is a quality indicator. Because groups or currents are voluntarily labeled by students based on the quality of the faculty, the curriculum is formed. To this end, the Regulation of the Ministry of Higher and Secondary Special Education of the Republic of Uzbekistan "On the Assessment of Students' Skills in Higher Education Institutions" has been developed [9], which aims to provide an impartial and accurate assessment of academic performance. It aims to

\footnotetext{
${ }^{2}$ Developed by the author based on data from Namangan State University.
} 
harmonize international experience, increase students' interest in science, increase the authority and responsibility of professors and teachers, and compare the quality of education with the results achieved.

Financial resources play a special role among the resources in the "black box". Currently, funding for higher education institutions is based on established standards per student, and it is assumed that the official figure does not differ significantly across universities. This standard represents the minimum costs for the educational process of the university. The rate is mainly set up, taking into account the salary costs of universities. At the same time, there is a clear need for a significant increase in financial resources for logistics and R\&D.

The above analyzes are based on the use of indirect measurements, which define the methods of modeling economic diagnostics. Therefore, a systematic review of system data, research using statistical techniques, the use of economic and mathematical models, and the use of linear programming to achieve quantitative expression goals are required. The economic diagnostics of higher education can be divided into three stages:

1. Quantitative evaluation. Analytical procedures are used to measure quantitative indicators (to make them acceptable for analysis) and to make decisions. It also reveals the existence of object-specific quantitative links and regularities.

2. Creating a mathematical model. Mathematical processing of indicators is represented by objectspecific regularities and mathematical links. Typically, data is presented in the form of tables or formulas that give an indication of how close an object's activity is to expected results and its meaningful analysis.

3. Finding solutions to optimize the operation of the facility. In the mathematical model, the factors affecting the activity of an object are represented as variables. The analysis provides an integral indicator of the number of variables (which is targeted at the object).

Thus, mathematical modeling allows optimizing the path in the "resource-result" chain by quantifying the expected results. In this regard, economic and mathematical modeling appears to be an important part of the economic diagnosis of HEIs. Generally, models can be built on a variety of bases: 1) the characteristics of the actual existing object or the models that simulate activity; 2) modeling or other models of any theoretical imagination. Both types of models can be used in the economic diagnosis of HEIs. It is possible to construct a model, to study the model, and to draw conclusions about the actual state of the object based on the model. One of the most challenging tasks in modeling economic economics in universities is to select and summarize specific indicators or indicators. When describing learning outcomes, factors may not be represented by only one indicator or may be combined with different factors. In these cases, there is a difficulty in identifying the indicators, that is, choosing a factor to interpret the result.

Therefore, the quality of higher education cannot be described by one indicator or it is necessary to summarize several indicators. From a mathematical point of view, these indicators are known as multidimensional points in space. When creating a model of the result, a multidimensional point is required. In this case, the results appear as integral amounts and the individual elements do not have the same weight. At the same time it is necessary to study the formative factors of the result according to the weight and dynamics of the different elements. Or, the behavior of factors is modeled and their relation to the outcome elements is investigated.

In general, the performance indicators that characterize the activities of the HEIs should be chosen in such a way that they are significantly related to the financial, economic and other resources and provide sound reasoning. The existing statistics on higher education are not sufficiently well established. Statistical data on the financial and economic resources of higher education are of a general nature and are not sufficient to make reasonable judgments about the actual dynamics of resources.

\section{CONCLUSION AND RECOMMENDATIONS}

1. Development of higher education is determined by the priorities of the national strategy. In the division of labor, quality of higher education and capacity building are required. This will ensure full participation of people in the developing innovation economy and thus, their well-being.

2. Higher education today requires the ability to create high value added in science and technology and innovation. At the same time, the quality of higher education is a guarantee of economic stability. 
3. The economic analysis of the quality of higher education, the identification of financial, economic and management problems, the assessment and forecasting of the ability of HEIs to achieve their goals in the context of constant external and internal factors requires strict adherence to the principles of economic diagnostics. In this regard, it is important to determine the impact of economic diagnostic costs on the quality of education and to compare the expected effects.

4. Economic diagnostics and modeling of the quality of higher education is a complex process. This process involves the combination of indicators of different contents (eg the volume of educational services and the volume of scientific products). In this case, it is necessary to find the unit of measure that is common to different indicators. In these cases, indicators that do not participate in the formulation may also be included in the list. Therefore, the formation of performance indicators is a complex task that is both horizontal (overall assessment of individual teacher activities) and vertical (generalized by department, faculty, and university).

5. Aggregation in the field of material production is often carried out using prices. However, there is a partial loss of information in the aggregation process. This is because even prices do not fully represent all the results of production. In education, the situation is much more complicated. It is not a mistake to summarize the income for education services as a single integral result by summing up the income for scientific products. However, in this process, the qualitative improvement of faculty, the accumulation of knowledge resources in higher education institutions, and the positive impact of HEIs on many processes in society are ignored. Therefore, qualitative analysis is always necessary when examining the results.

6 . The quality of education is one of the key factors that ensure the economic sustainability of higher education in the context of market relations. From this point of view, economic diagnostics may be considered as an important component of the quality of higher education, and its widespread implementation will contribute to a more reliable and effective diagnosis of the HEI.

7. Reliable and effective economic diagnostics of the quality of higher education depends on the following activities:

Defining the official classification of resources that support the activities of universities and maintaining their statistics;

Development of a system of indicators and statistics on the quality of education;

To rely on official statistics when determining the rankings of universities;

Development and implementation of integrated indicators based on the volume and quality of educational services of the university, the scientific and pedagogical potential of the faculty and the results of scientific activity.

\section{REFERENCES}

1. Mirziyoev Sh.M. Together we will build a free and prosperous, democratic Uzbekistan. Speech at the joint meeting of Chambers of Oliy Majlis dedicated to the inauguration of the President of the Republic of Uzbekistan. 13-14.

2. The Resolution of the President of the Republic of Uzbekistan dated June 5, 2018 N PP-3775 "On additional measures to improve the quality of education in the higher educational institutions and their active participation in large-scale reforms in the country". http://www.lex.uz/docs/3765586

3. Naimushin A.I. The structure of the education quality management system: the main directions of development // J. Innovative technology. - 2004, No. 1. S. 7.

4. Lazar Vlasceanu, Laura Griinberg, and Dan Parlea. (2004). Quality Assurance and Accreditation: A Glossary of Basic Terms and Definitions. Bucharest: UNESCO [ISBN 92-9069-178-6].

5. Levshina V.V. Development of the methodology of creating a quality management system of a university // J. University Management. - 2003, No. 2. P. 1.

6. Mirkurbanov N., Anoshkina V., Danilova E. Higher education in Uzbekistan: status and recommendations // J. Analytical note. - 2009. No. 1 (12), B. 24-28.

7. Karimov A.A., Peregudov L.V. Fundamentals of the monitoring and quality management system of higher education. - T .: 2003. p. 46 ;;

8. Saidov M. Management and Economics of Higher Education. - T.: 2002. b. 51.

9. Drohobytsky I.N. System analysis in economics: mathematical methods in economics, applied informatics.-M $\quad \therefore$ 2011.https://economics.studio/metodyi-ekonomike-matematicheskie/modelchernogo-yaschika-86127.html 
10. "Regulation on the assessment system of student learning in higher education institutions " http://www.edu.uz/en/pages/terms-rated

11. Spiridonova S. Management of the quality of educational services in the system of higher professional education // J. Vestnik, 2002. http://www.vestnik.vsu.ru/pdf/educ/2002/02/spiridonova.pdf

12. Bazarbekova A.D. Economic diagnostics of private higher education activities: organization and methodology// Procedia Economics and Finance $5 \quad$ (2013) $93 \quad$ - 102. http://booksc.org/book/25090701/b2a361 